\title{
Handling Qualities of a New Last-Mile Vehicle
}

\author{
Jordi D’hondt, Dominiek Degryse¹, Eric Demeester², Peter Slaets³, Marc Juwet \\ ${ }^{1}$ Department of Robotics, Automation and Mechatronics, KU Leuven, Gent, Belgium \\ ${ }^{2}$ Department of Robotics, Automation and Mechatronics, KU Leuven, Diepenbeek, Belgium \\ ${ }^{3}$ Department of Robotics, Automation and Mechatronics, KU Leuven, Group T Leuven, Belgium \\ Email: jordi.dhondt@kuleuven.be, dominiek.degryse@kuleuven.be, eric.demeester@kuleuven.be,peter.slaets@kuleuven.be, \\ marc.juwet@kuleuven.be
}

How to cite this paper: D'hondt, J., Degryse, D., Demeester, E., Slaets, P. and Juwet, M. (2022) Handling Qualities of a New Last-Mile Vehicle. Journal of Transportation Technologies, 12, 137-158. https://doi.org/10.4236/jtts.2022.121009

Received: December 7, 2021

Accepted: January 25, 2022

Published: January 28, 2022

Copyright (C) 2022 by author(s) and Scientific Research Publishing Inc. This work is licensed under the Creative Commons Attribution International License (CC BY 4.0).

http://creativecommons.org/licenses/by/4.0/

\begin{abstract}
This paper assesses the vehicle dynamics of a new cargo bike concept developed for euro pallet sized cargo. The cargo bike developed is for last-mile delivery. Different aspects of manoeuvrability and stability are examined using a series of manoeuvres based on tests from the automotive industry combined with bicycle industry regulations. These manoeuvres objectively evaluate and determine the handling capabilities of the cargo bike concept. Those tests can be compared using the results of the benchmark vehicles. The results conclude the new cargo bike has proper vehicle dynamics above the majority of benchmark vehicles but there is still room for improvement.
\end{abstract}

\section{Keywords}

Cargo Bike, Last-Mile Delivery, Handling Qualities, E-Commerce

\section{Introduction}

The increase of e-commerce and the general focus on sustainability increases the implementation of cargo bicycles for last-mile logistics. Economically the transition also makes sense. Electric bikes are $60 \%$ faster than vans in city centres [1] and are more cost-effective than delivery trucks [2].

Currently, $51 \%$ of all motorised trips can be done using a bike or cargo bike [3]. Many variations of cargo bikes already exist but there is still room for improvement. These cargo bikes transport loads up to $150 \mathrm{~kg}$, and have a high cargo hold, or cargo hold only reachable from the top. This type of cargo hold does not allow for high weight single package transport such as a washing machine or a TV. 
Due to the rising demand for cargo bikes and the increasing shift to sustainable logistics, a novel concept cargo bike is developed. Market research shows containerisation is desired [4]. This allows pre-sorting in transportation hub which can easily be transported to pick up points to easily load the cargo bike. The cargo bike is able to carry a euro pallet sized cargo with a maximum payload of $250 \mathrm{~kg}$. This research focuses on the handling quality of the concept vehicle according to the load and objectively compares it for different types of electric bikes. To objectively evaluate the vehicle dynamics, a series of manoeuvres are carried out. The tests are based on a comparative study for multitrack electric bicycles [5]. The concept vehicle can perform these tests and compare the results with other cargo bikes.

\section{Cargo Bike Concept}

\subsection{Wear and Tear}

Our market research shows the current limitations of cargo bikes. The majority of the cargo bikes are developed for commercial use and have a lot of integrated standard bicycle components. Those components are not suitable for industrial use. They require a lot of maintenance and malfunctioning can occur. A mid-drive motor is the most common way of electrical assistance. This configuration transfers the combined human and electrical power through the chain to the wheels. The higher stress causes extra wear on the drive chain which can lead to premature failure [6]. According to bicycles couriers, flat tires and broken chains are the most frequent breakdowns.

\subsection{Cargo Size}

Cargo bikes suffice for current e-commerce delivery but bike couriers are complaining about the bike's total cargo capacity. The cargo bike is usually fully loaded when the couriers leave for their delivery tour. In addition, they would like to be able to take more load with them during their delivery tour. Sometimes trailers are added to expand the cargo capacity. Most of the cargo bike designs have a cargo hold which is often only reachable from the top. This doesn't allow for easy load/unloading of heavy products such as washing machines and TV. Cities implement low-emission zones and circulation plans banning vans in city centres improving the environment. Cargo bikes are a sustainable and economical alternative and need to deliver more products and larger parcels such as large electric appliances (e.g. refrigerator, dishwasher, TV-screen, ...). For easy loading/unloading, a pre-sorted city container or a euro pallet can be placed on the cargo hold.

\subsection{Manoeuvrability}

Because the cargo can be the major part of the gross weight of the vehicle, the cargo has an impact on the stability and manoeuvrability of the cargo bike. Twowheeled cargo bikes manoeuvrability differs depending on the transported load. 
A fully loaded bike has a higher Moment of Inertia (M.O.I.) [7] making it more difficult to manoeuvre. Furthermore, poor loading of the cargo space creates an imbalance requiring more focus to drive and shifting of the cargo could cause the driver to lose control [8].

Three-wheeled cargo bikes however are stable at low speeds but can tip over during fast cornering with full cargo. This is mainly due to the high centre of gravity and the small wheelbase [9] [10]. The cargo causes a high centre of gravity and the driver is barely able to lean in the turn compared to a conventional bike. A tilting tricycle improves stability [11].

\subsection{New Last-Mile Concept}

The Last-Mile Vehicle (LMV) is a novel concept developed for last-mile delivery (Figure 1). The vehicle is designed to transport euro-pallet sized cargo with a maximum load of $250 \mathrm{~kg}$. Being able to transport a pre-packaged city container or euro pallet smoothens the transition from a transportation hub to the final destination.

To ensure that the driver does not have an obstructed view, the cargo bed is located behind the driver. The euro pallet sized cargo bed is located between the rear-wheels to ensure a low centre of gravity. It has a load capacity of around 250 $\mathrm{kg}$. The vehicle consists of 2 modules, a rear cargo module and a front cyclist module. The cargo bike is powered using two Brushless DC (BLDC) hub rearwheels each capable of $2000 \mathrm{~W}$ peak power with a maximum torque of $90 \mathrm{Nm}$. The motors have an independent current control creating an electrical differential. This allows natural cornering and doesn't steer the vehicle in one direction which is often the case with 1 WD delta tricycles. The front cyclist module is connected with a hinge enabling the cyclist to lean during corners. This creates a natural cycling feeling improving the manoeuvrability of the LMV.

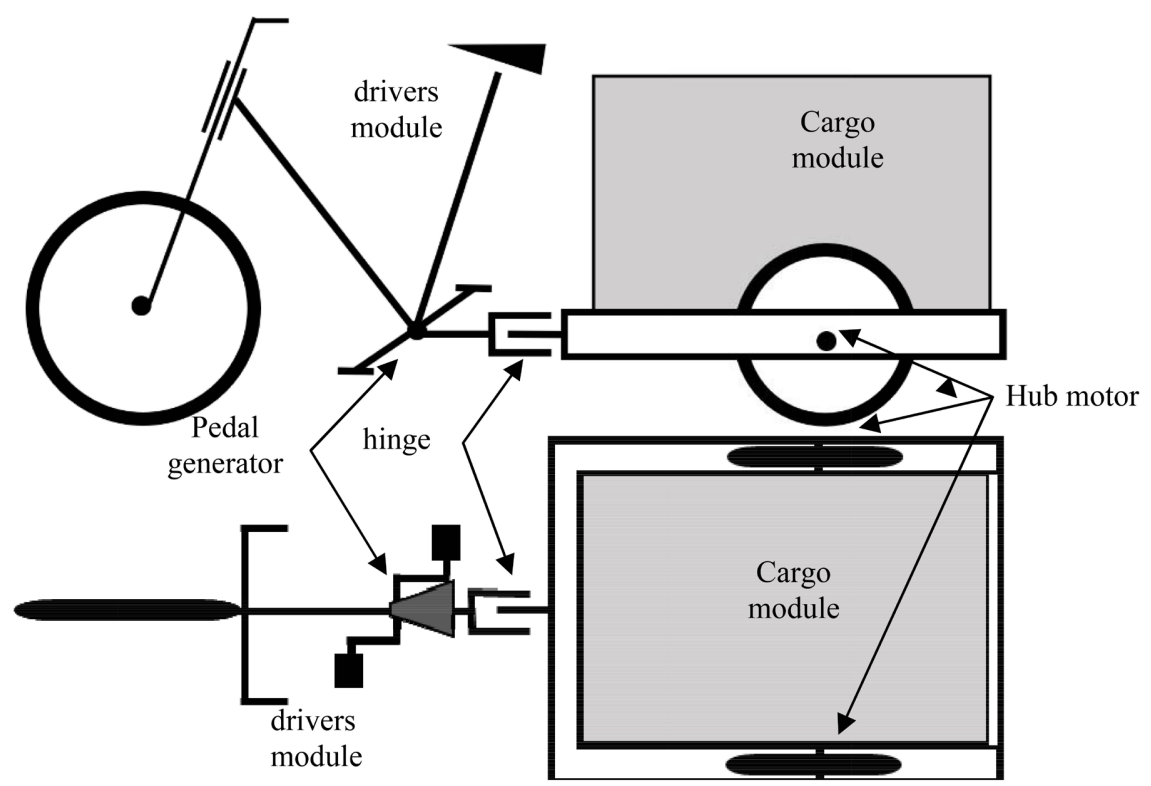

Figure 1. LMV concept. 
Hinging the bicycle module and the cargo module allows the driver to lean during manoeuvres without noticeable influence from the load. This hinge is constructed using a slewing ring bearing allowing only one rotational degree of freedom. The cargo module will not lean during cornering. The position and orientation are determined to obtain a proper balance between stability and manoeuvrability. Bicycles become more difficult to balance at lower velocities [12]. A torsion spring consisting of an elastomer structure is added to improve the stability during low velocities. This combines torsion and damping improving the stability during low velocities.

Due to regulatory constraints [13], the vehicle has a maximum width of 1 meter. The width of a euro pallet of $0.8 \mathrm{~m}$ remains less than $100 \mathrm{~mm}$ available wheel dropout. This results that there is no room available for the mechanical brakes. That's why the cargo bike uses regenerative braking. The front-wheel has an additional mechanical brake. Regenerative braking is controlled by a brake lever which proportionally regulates the braking of each motor. While braking, each motor recharges the vehicle's battery. Li-ion batteries have limited energy they can safely absorb. The excess braking energy is consumed using a heat sink to avoid damaging the battery. For extra road grip, the wheel motors have individual software implemented ABS limiting the slip improving the safety of the vehicle.

The flexible construction between the modules prevents a traditional bicycle drive train. Tilting would misalign the chain and cause a derailment. Another flexible mechanical coupling is an alternative that would make it more complex, expensive and would require a higher wheel dropout. An electrical drivetrain doesn't require extra installation room and has fewer design constraints.

The electrical drivetrain consists of 2 wheel motors to propel and a mid-motor used as a pedal generator. The pedal generator drive controls the pedal resistance simulating a natural pedal feeling. The force applied on the pedal generator combined with a proportional rotational difference controls the wheel motors. The direct-drive hub motors don't have an integrated freewheel so it allows control in both directions. This allows the LMV to have a forward and backward walking support function.

A prototype was constructed to assess the optimal position and orientation to obtain an optimal balance between stability and manoeuvrability. The second prototype is used to perform the manoeuvres (Figure 2). Since the bicycle is developed as a cargo bike where the load changes constantly, the tests are conducted with different loads. The drivers have extensively tested the vehicle before the manoeuvres are performed to get used to the vehicle and get proper results.

\section{Benchmark Models}

The LMV is compared with QuadRad, City Shopping, Babboe Big and Babboe City (Figure 3 ). These cargo bikes are a good representation of the different 


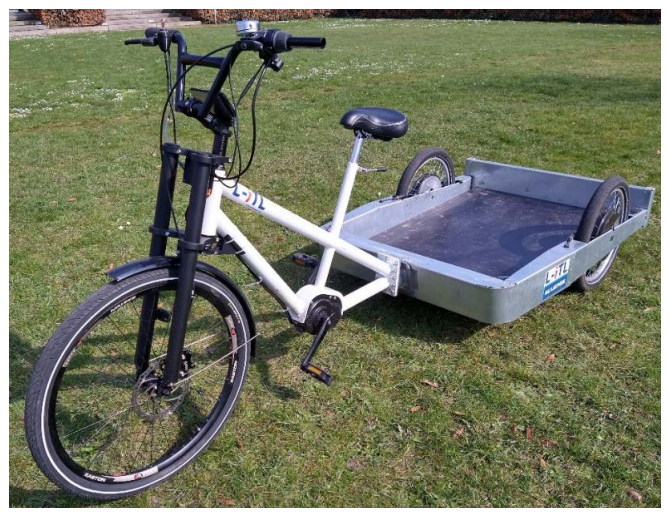

Figure 2. LMV prototype.

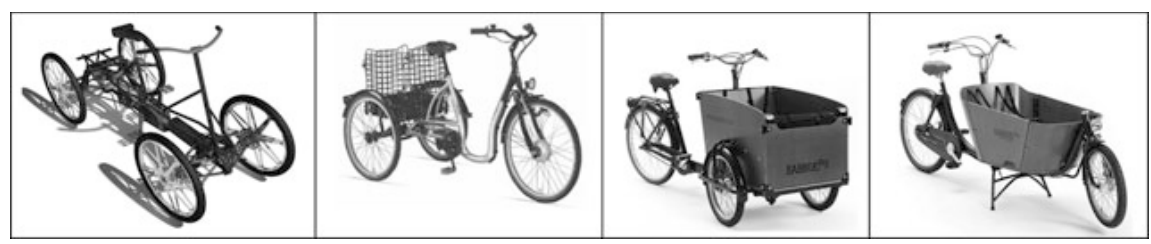

Figure 3. QuadRad, city shopping bike, babboe big, babboe city (from left to right).

types of cargo bikes. A four-wheeled bike, a three-wheeled bike with two rear wheels, a three-wheeled bike with two front wheels and a long John (two-wheeled bicycle with the cargo hold in front of the driver). These configurations represent the majority of cargo bikes.

The QuadRad is a four-wheeled bicycle with pedal assistance. The concept vehicle can carry up to $180 \mathrm{~kg}$ behind the driver and is designed for commercial applications and everyday use. The City Shopping Bike has a fixed delta frame with 2 rear wheels and 1 front wheel. With a revenue load of $22 \mathrm{~kg}$, the City Shopping Bike is developed for everyday life use. The Babboe Big is a threewheeled cargo bike with 2 front wheels and one rear wheel. This is a tadpole design. The Babboe Big is designed to transport children safely on a bench, which is equipped with a seat belt. It can also be used to transport cargo up to a load of $100 \mathrm{~kg}$. The Babboe City is a Long John design. It is a two-wheeled bicycle with a cargo area between the driver and the front wheel. The Babboe City can carry 80 $\mathrm{kg}$. The LMV has a delta design with a flexible connection between the cargo module on the rear and the driver module on the front. The LMV is developed for commercial use and can carry $250 \mathrm{~kg}$ of cargo. All values are summarized in Table 1.

City Shopping, Babboe Big and Babboe Big are mechanically driven. QuadRad is mechanically driven with extra assistance from a Mid-Engine motor of $250 \mathrm{~W}$ and a maximum torque of $70 \mathrm{Nm}$. The LMV is powered by 2 hub motors with a peak power of $2000 \mathrm{~W}$ and a maximum torque of $90 \mathrm{Nm}$ each. The power of the LMV exceeds the permitted $250 \mathrm{~W}$ for an e-bike. The LMV can be software limited so the nominal continuous power remains below $250 \mathrm{~W}$. In this case, no registration is required. 
Table 1. Technical specifications.

\begin{tabular}{|c|c|c|c|c|c|}
\hline & QuadRad & $\begin{array}{c}\text { City } \\
\text { Shopping }\end{array}$ & Babboe Big & Babboe City & LMV \\
\hline Wheel base (mm) & 1350 & 1320 & 1360 & 2000 & 2000 \\
\hline Wheel track (mm) & 730 & 635 & 725 & l & 910 \\
\hline Tyre size (in.) & 26 & 26 & $\begin{array}{l}26 \text { Rear } \\
20 \text { Front }\end{array}$ & $\begin{array}{l}26 \text { Rear } \\
20 \text { Front }\end{array}$ & $\begin{array}{l}20 \text { Rear } \\
26 \text { Front }\end{array}$ \\
\hline $\begin{array}{l}\text { Chassis clearance } \\
(\mathrm{mm})\end{array}$ & 153.5 & 140 & 75 & 150 & 150 \\
\hline Drive concept & Mid-Engine & Mechanical & Mechanical & Mechanical & Series Hybrid \\
\hline Weight of vehicle $(\mathrm{kg})$ & 60 & 32.5 & 61 & 45.5 & 122.2 \\
\hline Revenu load (kg) & 180 & 22 & 100 & 80 & 250 \\
\hline Axle weight (kg) & $\begin{array}{l}\text { FA RA } \\
2436\end{array}$ & $\begin{array}{l}\text { FA RA } \\
9.523\end{array}$ & $\begin{array}{c}\text { FA RA } \\
4813\end{array}$ & $\begin{array}{l}\text { FA RA } \\
2223.5\end{array}$ & $\begin{array}{c}\text { FA RA } \\
30.891 .4\end{array}$ \\
\hline $\begin{array}{l}\text { turning clearance } \\
\text { circle }(\mathrm{m})\end{array}$ & 4.35 & 2.92 & 6.85 & 5.88 & 3.80 \\
\hline
\end{tabular}

The Babboe City and LMV benefit from a low centre of gravity since the cargo area is positioned between the wheels. This lowers the centre of gravity and increases stability. Due to the delta design, the City Shopping has the lowest turning circle followed by the LMV due to the larger wheelbase. Most vehicles have a higher load on the rear axle. The Babboe Big is the only one with a higher weight distribution due to the tadpole design. The LMV can carry the highest cargo load.

\section{Experimental Setup}

The components used in (electrical) cargo bicycles must meet certain standards. The bicycles braking characteristics must also comply with certain standards to ensure safety [14]. However, there are no standardised tests to evaluate the handling qualities of a cargo bike. The automotive industry uses standardized manoeuvres to assess the vehicle dynamics of a vehicle [15]. These tests are openloop control, meaning the result is independent of the driver. These tests are used to determine the vehicle's safety rating. There is no standard to evaluate a motorcycle's dynamic to the author's knowledge. Motorcycles have a series of tests but this is to evaluate the driver's skills.

The bicycle industry doesn't have standard tests to evaluate the handling qualities of the vehicle. This is due to the tinkering method and subjective evaluation which has been used for the past 200 years during the evolution of bicycles [16]. Furthermore, cycling doesn't require a driving licence which evaluates driving skills. Kooijman et al. summarize experiments used to evaluate different aspects of the handling qualities [17]. The manoeuvres performed as described in [5] are derived from the automotive industry test and adjusted to the bicycle industry. These manoeuvres allow an objective evaluation of the different vehicles. 


\subsection{Measurement Procedure}

The different manoeuvres are described according to Figure 4. The manoeuvres are set up using pylons.

The manoeuvres are not always performed at the desired speed. A difference in the performing speed changes the results and doesn't allow for proper comparison. To compensate for the speed variations, the measurements are corrected using Equation (1) [14].

$$
L_{k o r}=\frac{V_{s}^{2}}{V_{m}} * L_{m}
$$

where:

$$
\begin{aligned}
& L_{k o r}=\text { corrected length; } \\
& L_{m}=\text { measured length; } \\
& V_{s}=\text { prescribed test speed; } \\
& V_{m}=\text { measured test speed. }
\end{aligned}
$$

This compensation is applied in each manoeuvre using a specified velocity.

\subsection{Braking Test}

To ensure the safety of the vehicle, the braking capabilities requires evaluation. When any obstacles occur, the vehicle must be able to perform a controlled emergency stop. This test measures the braking capabilities at a given speed. An emergency stop is done at a velocity of $25 \mathrm{~km} / \mathrm{h}$. Braking is applied when the front wheel is between the pylons (Figure 5).

The test is carried out by applying the front-wheel brake, rear-wheel brake separately and combined. The emergency brake requires the vehicle to a full stop. The emergency brake is evaluated by measuring the distance from the pylons to the front wheel (stopping distance). The braking performance is also evaluated using the Mean Fully Developed Deceleration (MFDD) [18]. MFDD is calculated using Equation (2).

$$
d_{m}=\frac{V_{b}^{2}-V_{e}^{2}}{25.92 *\left(S_{e}-S_{b}\right)}
$$

where:

$$
\begin{aligned}
& d_{m}=\text { Mean Fully Developed Deceleration; } \\
& V_{1}=\text { vehicle speed when rider actuates the braking control; } \\
& V_{b}=\text { vehicle speed at } 0.8 V_{1} \text { in } \mathrm{km} / \mathrm{h} ; \\
& V_{e}=\text { vehicle speed at } 0.1 V_{1} \text { in } \mathrm{km} / \mathrm{h} ; \\
& S_{b}=\text { distance travelled between } V_{1} \text { and } V_{b} \text { in metres; } \\
& S_{e}=\text { distance travelled between } V_{1} \text { and } V_{e} \text { in metres. }
\end{aligned}
$$

These values are gathered from logged data of the hub motors. Those values can also be gathered using a camera system to measure the speed at corresponding positions. A low stopping distance has a good performance result while a high MFDD gives a good performance result. 


\section{Q Pylon \\ $\longrightarrow$ Driving direction}

Figure 4. Legend of manoeuvre setup.

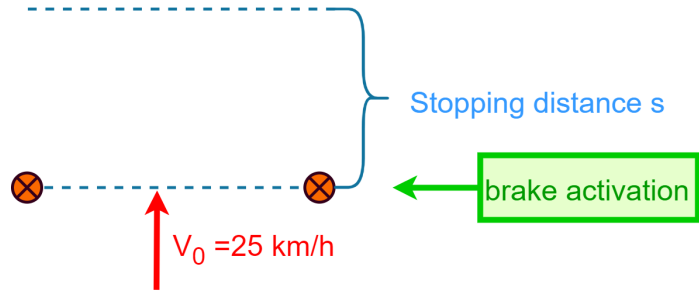

Figure 5. Emergency brake.

For category L1 (light-powered vehicle) the braking requirements are summarised in Table 2.

Since this vehicle is designed as a city delivery vehicle, the LMV will perform above mentioned with different cargo amounts. The vehicle has a cargo capacity of $200 \mathrm{~kg}$. Tests will be conducted with cargo varying between 0 and $200 \mathrm{~kg}$ load.

The LMV's primary breaking method is regenerative braking. The LMV is also equipped with a front-wheel hydraulic brake. To evaluate the regenerative braking, only the rear-wheel brake is applied. The braking energy charges the battery and dissipates the remaining energy to heat using a brake resistor. Braking with a high State of Charge (SOC) will direct more energy to the braking resistor. These tests are conducted on a high SOC and low SOC. Unfortunately, the efficiency of regenerative braking reduces significantly at lower speeds [19].

\section{3. $\mu$-Split Braking Test}

The braking test is expanded upon for multitrack vehicles by braking on different friction surfaces. This test is done at a velocity of $25 \mathrm{~km} / \mathrm{h}$. The previously mentioned paper tests the braking on ice, but this is too difficult to set up. The braking test will be performed on the pavement on one side. The other side is driven on loose gravel, steel sheets, polished concrete or low friction tape around one tire to obtain a friction coefficient below 0.15 [20]. The difference in friction will cause a different braking reaction on the left and right wheels. Distortion after braking is measured to examine the stability of the vehicle during an emergency brake as seen in Figure 6.

The automotive industry uses Electronic Stability Controller (ESC) systems to improve control and reduce collisions [21]. Cargo bikes are not equipped with ESC. City centres have multiple areas with different road surfaces (i.e. tram rails, smooth tiles next to the pavement, road markings, ...) and $\mu$-split brake can occur. A low distortion indicates a stable vehicle with less likely to lose control.

\subsection{Steady-State Turn}

A steady-state turn lets the driver drive around a circle with a radius of 4 meters 
as seen in Figure 7. The driver drives as fast as possible around the circle while remaining stable with all wheels on the ground.

The maximum mean speed of at least one rotation is measured with its corresponding lateral acceleration. A mobile phone is attached to the saddle tube below the driver to measure the accelerations. A stable and controllable vehicle reaches a high maximum vehicle. A low lateral acceleration means a low sideways force applied on the driver and results in more comfort. A high lateral acceleration causes a high outwards force which is pushing the driver outwards and is highly uncomfortable. Depending on the centre of gravity and the wheelbase, the vehicle remains stable during high lateral accelerations. This manoeuvre tests the maximum velocity the vehicle can drive around the circle.

Table 2. Braking requirement.

\begin{tabular}{ccc}
\hline & Stopping distance & MFDD \\
\hline $\begin{array}{c}\text { Front wheel(s) brkaing only } \\
\text { Rear wheel(s) braking only }\end{array}$ & $\mathrm{S} \leq 0.1^{\star} \mathrm{V}+0.0111^{\star} \mathrm{V}^{2}$ & $\geq 3.4 \mathrm{~m} / \mathrm{s}^{2}$ \\
$\begin{array}{c}\text { Vehicles with CBS or split service } \\
\text { brake systems: for laden and lightly } \\
\text { loaded conditions }\end{array}$ & $\mathrm{S} \leq 0.1^{*} \mathrm{v}+0.0143^{*} \mathrm{~V}^{2} \mathrm{~V}+0.0087^{\star} \mathrm{V}^{2}$ & $\geq 2.7 \mathrm{~m} / \mathrm{s}^{2}$ \\
$\begin{array}{c}\text { Vehicles with CBS-secondary service } \\
\text { brake systems }\end{array}$ & $\mathrm{S} \leq 0.1^{*} \mathrm{~V}+0.0154^{*} \mathrm{~V}^{2}$ & $\geq 2.5 \mathrm{~m} / \mathrm{s}^{2}$ \\
\hline
\end{tabular}

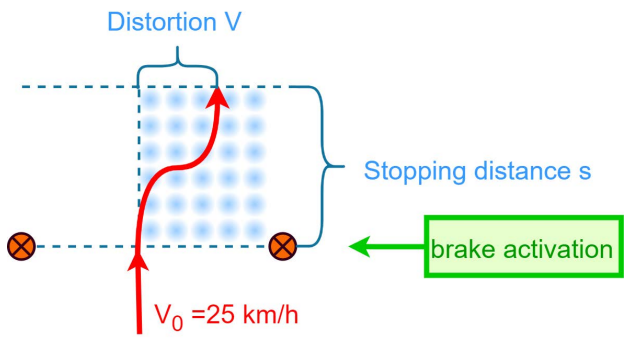

Figure 6. $\mu$-split brake.

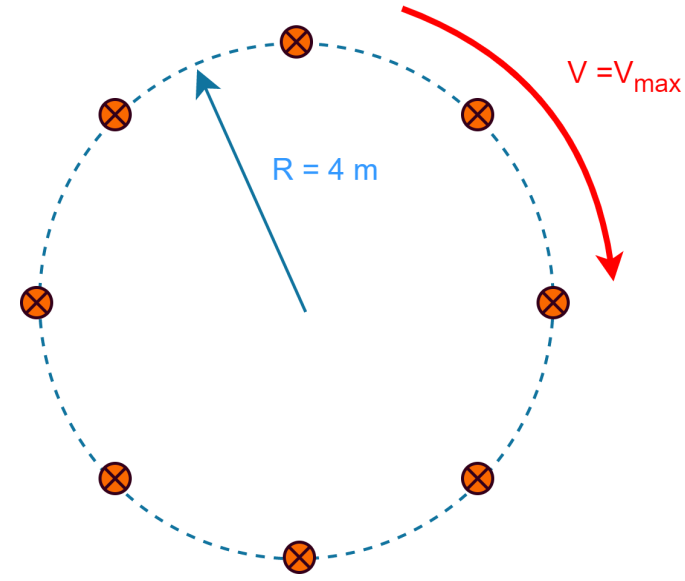

Figure 7. Steady-state turn. 


\subsection{Figure of Eight}

The figure of eight is an addition to the steady-state turn, where the control of the vehicle is further examined. A figure of eight is driven around two pylons standing 10 meters apart as seen in Figure 8.

This measures the maximum mean speed of at least one complete eight with the corresponding absolute mean acceleration. The speed will be lower than the steady-state turn and the result will depend on the driving skills.

\subsection{Prompt Steering}

Prompt steering evaluates the ability of sharp turns. Driving in city centres often requires short turns due to narrow streets or avoiding obstacles. The driver drives through two pylons at a constant velocity. The driver has to turn as short as possible and the distance required to make a $90^{\circ}$ turn is measured as seen in Figure 9.

These tests are conducted at 10,15 and $20 \mathrm{~km} / \mathrm{h}$ if the manoeuvre is deemed safe. The steering is executed without braking. The minimal possible distance should be measured at 2 meters after the turn, but due to the long wheelbase of the LMV, the distance is measured when the vehicle is perpendicular to the starting orientation. A manoeuvrable and controllable vehicle will result in a short turning distance.

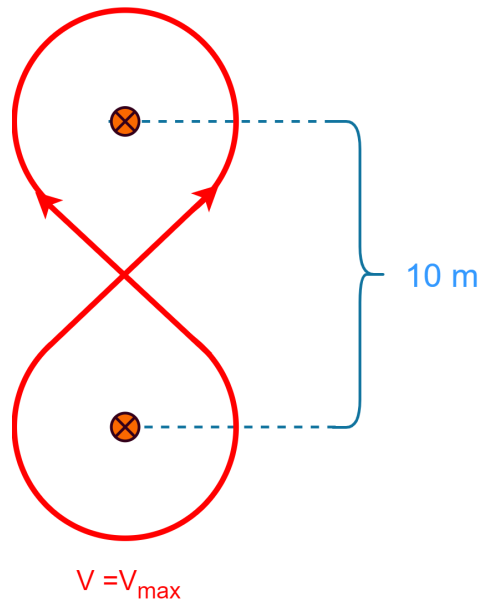

Figure 8. Figure of eight.

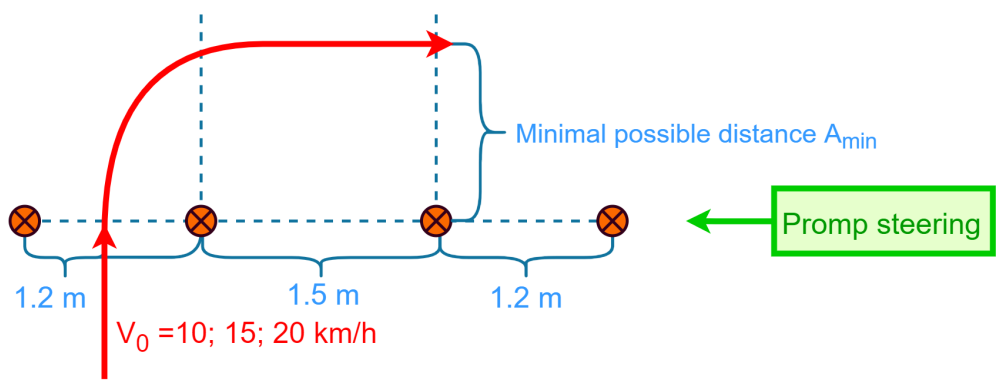

Figure 9. Prompt steering. 


\subsection{Double Lane Change}

A double lane change and a slalom require quick changes and proper control of the vehicle. The double lane change examines the highest possible speed for the vehicle driving through the obstacle. The maximum mean velocity of the course is measured. An adaptation was made in the manoeuvre to account for wider vehicles as seen in Figure 10.

The consecutive bends review the controllability and stability. Since the vehicle must drive between the pylons, extra width of a vehicle requires extra sway to accomplish the manoeuvre making it more difficult. This test examines if it's possible to complete the course error-free at the desired speed.

\subsection{Slalom}

The slalom is executed using fixed distances at $3 \mathrm{~m}$ for the short slalom and $4 \mathrm{~m}$ for the long slalom as seen in Figure 11. The short slalom is done at $10 \mathrm{~km} / \mathrm{h}$ and the long slalom at $15 \mathrm{~km} / \mathrm{h}$.
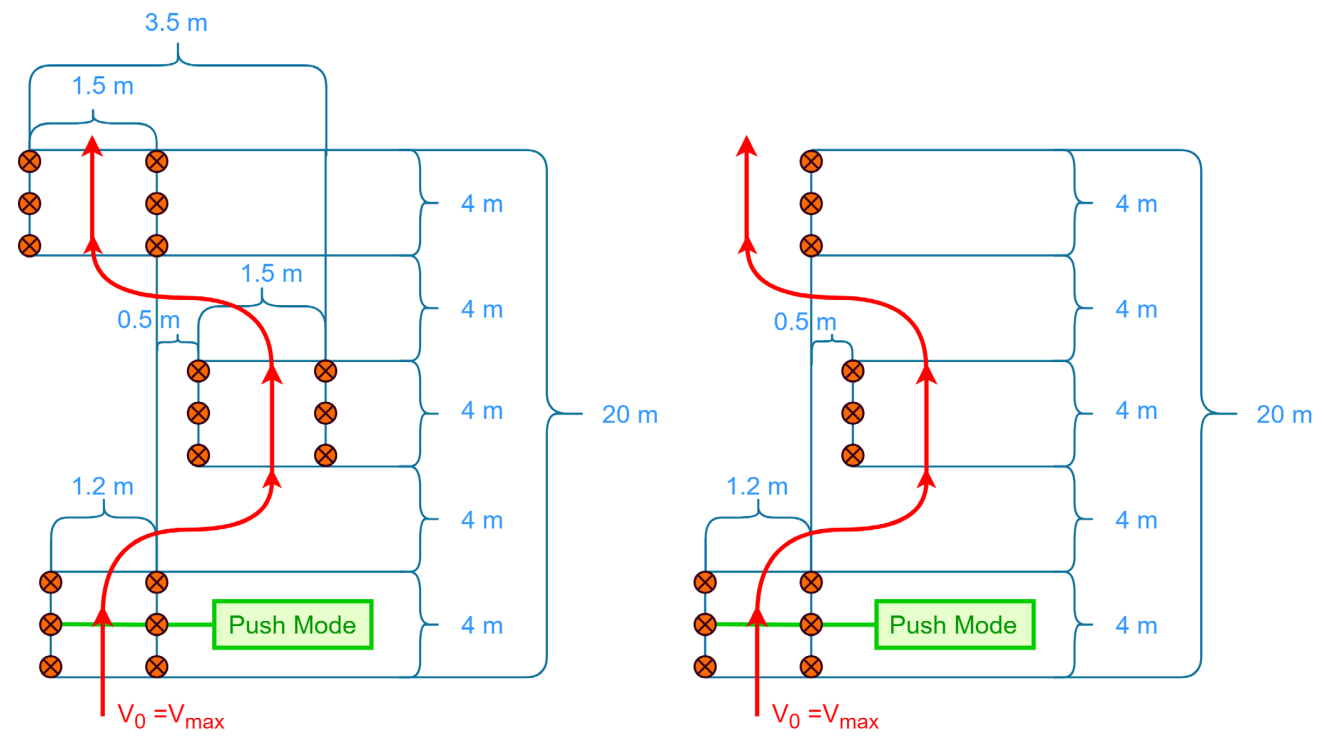

Figure 10. Double lane change.

Short:

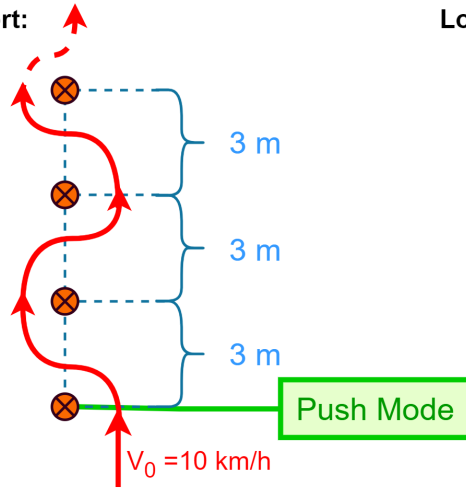

Figure 11. Slalom. 
The consecutive bends review the controllability and stability. Since the vehicle must drive between the pylons, extra width of a vehicle requires extra sway to accomplish the manoeuvre making it more difficult. This test examines if it's possible to complete the course error-free at the desired speed.

\subsection{Summary}

Above mentioned manoeuvres are summarised in Table 3.

Due to the nature of the vehicles, all manoeuvres are closed-loop manoeuvres as the driver contributes a major part to the overall weight of the vehicle and the centre of gravity of the vehicle. The driver's posture and grip change the stability of the vehicle [22]. The manoeuvres which are said to be based on tests from the automotive industry are similar to tests performed during a motorcycle exam which evaluate the skills of the driver (Figure 12). The motorcycle manoeuvring test contains just as the bicycle tests: a slalom, an emergency stop (brake testing), a figure of eight, avoidance (prompt steering), cornering (steady-state circle). The driver requires certain driving skills to pass these tests. These driving skills are acquired through extensive practice. Fortunately, all drivers are frequent cyclists and only required a short driving period to get used to the concept vehicle. The manoeuvres are conducted multiple times and the best results are used as the test are an indication of what is possible with the vehicle.

The prescribed test was performed with the LMV. These tests evaluate the handling qualities and compare them with the benchmark vehicle.

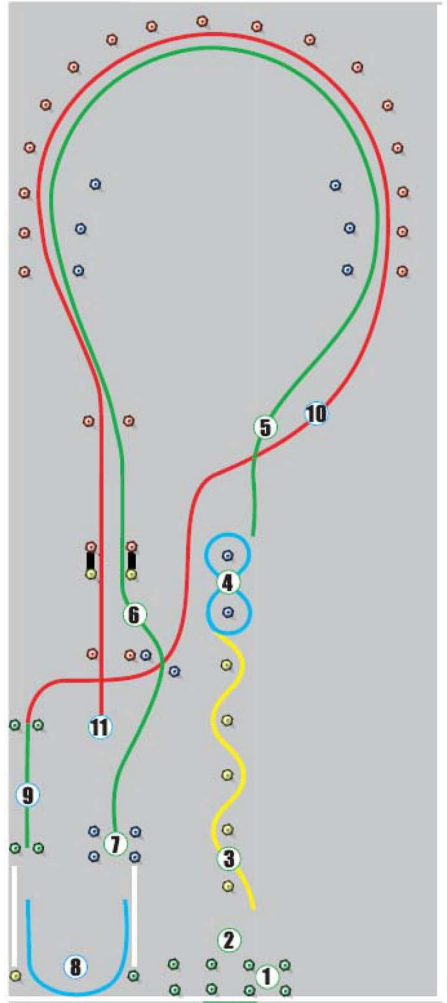

\section{MOTORCYCLE MANOEUVRING Left Circuit}

1 On and off the stand 2 Wheel the machine 3 Slalom 4 Figure of eight $530 \mathrm{kph} / 19 \mathrm{mph}$ circuit $650 \mathrm{kph} / 32 \mathrm{mph}$ circuit

7 Controlled stop

8 U-turn

9 Slow ride

$1030 \mathrm{kph} / 19$ circuit ride

$1150 \mathrm{kph} / 32 \mathrm{mphemergencybrake}$

\section{MOPEDS}

For all mopeds, speed requirements are $50 \mathrm{kph} / 19 \mathrm{mph}$

Diagram for illustrative purposes only. For details of the circuit measurements, please refer to the DSA Website.

Figure 12. Motorcycle manoeuvring circuit. 
Table 3. Summary of manoeuvres.

\begin{tabular}{|c|c|c|c|}
\hline Manoeuvre & Performed speed & Tested aspect & Performance measure \\
\hline Braking test & $25 \mathrm{~km} / \mathrm{h}$ & $\begin{array}{l}\text { Control } \\
\text { Safety }\end{array}$ & Braking distance \\
\hline$\mu$-split braking test & $25 \mathrm{~km} / \mathrm{h}$ & $\begin{array}{l}\text { Control } \\
\text { Safety }\end{array}$ & Distortion \\
\hline Steady-state turn & Max. speed & Lateral stability & $\begin{array}{c}\text { Max. speed } \\
\text { Lateral acceleration }\end{array}$ \\
\hline Figure of eigth & Max. speed & $\begin{array}{l}\text { Lateral stability } \\
\text { control }\end{array}$ & $\begin{array}{c}\text { Max. speed } \\
\text { Lateral acceleration }\end{array}$ \\
\hline Prompt steering & 10,15 and $20 \mathrm{~km} / \mathrm{h}$ & $\begin{array}{c}\text { Stability } \\
\text { Control } \\
\text { Manoeuvrability }\end{array}$ & Min. turning distance \\
\hline $\begin{array}{c}\text { Double lane } \\
\text { change }\end{array}$ & Max. speed & Manoeuvrability & Max. speed \\
\hline Slalom & $\begin{array}{l}10 \mathrm{~km} / \mathrm{h}-3 \mathrm{~m} \text { cones } \\
15 \mathrm{~km} / \mathrm{h}-4 \mathrm{~m} \text { cones }\end{array}$ & $\begin{array}{c}\text { Performance } \\
\text { Control } \\
\text { Manoeuvrability }\end{array}$ & Max. speed \\
\hline
\end{tabular}

All manoeuvres with the LMV are performed at a constant tire pressure of 6 bar for the rear wheels and 3.5 bar for the front wheel. These tests are performed on the pavement. The tests are performed with the LMV with and without load.

The manoeuvres were performed by 5 participants. The participants were all male with an age between 20 and 30 years. Every participant has experience driving bicycles but only 2 are bicycle couriers. The participants represent around 75\% of bicycle couriers according to courier companies.

\section{Results}

A summary of the performed manoeuvres is described. The results of the LMV are added to the results of the benchmark vehicles.

\subsection{Braking Test}

The full application rear brake at $25 \mathrm{~km} / \mathrm{h}$ is used to evaluate the regen braking of the LMV. The current prototype has no place for mechanical rear brakes so the vehicle only brakes using regen braking on the rear wheel hub motors. The QuadRad has the best braking distances and is the only vehicle passing its own acceptable braking distance as can be seen in Table 4 . The maximum regulatory braking distance for a rear-wheel test at a speed of $25 \mathrm{~km} / \mathrm{h}$ is $11.43 \mathrm{~m}$ [18]. This is acceptable for the City Shopping and the Babboe Big. The regen braking has a proportional increase in braking distance according to the weight progressing from $7.9 \mathrm{~m}$ to $12.92 \mathrm{~m}$ with no cargo and $200 \mathrm{~kg}$ cargo respectively. The braking distance is currently not sufficient with a cargo of $160 \mathrm{~kg}$ or higher. The brake test only complies with the MFDD guidelines only up to a load of $60 \mathrm{~kg}$. This is due to the poor efficiency of regenerative braking at lower speeds [19]. MFDD 
Table 4. Full rear brake application $25 \mathrm{~km} / \mathrm{h}$.

\begin{tabular}{|c|c|c|c|c|c|c|c|c|c|}
\hline \multicolumn{5}{|c|}{ QuadRad } & \multicolumn{5}{|c|}{ City Shopping } \\
\hline $\begin{array}{c}V_{m} \\
(\mathrm{~km} / \mathrm{h})\end{array}$ & $\begin{array}{l}\text { LOAD } \\
(\mathrm{m})\end{array}$ & $\begin{array}{l}S_{m} \\
(\mathrm{~m})\end{array}$ & $\begin{array}{l}S_{\text {kor }} \\
(\mathrm{m})\end{array}$ & $\begin{array}{c}\text { Acceptable } \\
\text { braking } \\
\text { distance }\end{array}$ & $\begin{array}{c}V_{m} \\
(\mathrm{~km} / \mathrm{h})\end{array}$ & $\begin{array}{l}\text { LOAD } \\
(\mathrm{m})\end{array}$ & $\begin{array}{c}S_{m} \\
(\mathrm{~m})\end{array}$ & $\begin{array}{l}S_{\text {kor }} \\
(\mathrm{m})\end{array}$ & $\begin{array}{c}\text { Acceptable } \\
\text { braking } \\
\text { distance }\end{array}$ \\
\hline 25.3 & 180 & 6.7 & 6.54 & $\sqrt{ }$ & 24.8 & 22 & 7.15 & 7.27 & $\sqrt{ }$ \\
\hline 25.1 & 180 & 6.6 & 6.55 & $\sqrt{ }$ & 25 & 22 & 7.5 & 7.6 & $\sqrt{ }$ \\
\hline 25 & 180 & 6.6 & 6.6 & $\sqrt{ }$ & 24.9 & 22 & 7.3 & 7.3 & $\sqrt{ }$ \\
\hline \multicolumn{5}{|c|}{ Babboe Big } & \multicolumn{5}{|c|}{ Babboe City } \\
\hline $\begin{array}{c}V_{m} \\
(\mathrm{~km} / \mathrm{h})\end{array}$ & $\begin{array}{l}\text { LOAD } \\
(\mathrm{m})\end{array}$ & $\begin{array}{l}S_{m} \\
(\mathrm{~m})\end{array}$ & $\begin{array}{l}S_{k o r} \\
(\mathrm{~m})\end{array}$ & $\begin{array}{c}\text { Acceptable } \\
\text { braking } \\
\text { distance }\end{array}$ & $\begin{array}{c}V_{m} \\
(\mathrm{~km} / \mathrm{h})\end{array}$ & $\begin{array}{l}\text { LOAD } \\
(\mathrm{m})\end{array}$ & $\begin{array}{l}S_{m} \\
(\mathrm{~m})\end{array}$ & $\begin{array}{l}S_{k o r} \\
(\mathrm{~m})\end{array}$ & $\begin{array}{c}\text { Acceptable } \\
\text { braking } \\
\text { distance }\end{array}$ \\
\hline 24.7 & 80 & 7.30 & 7.48 & $\sqrt{ }$ & I & & & & $\mathrm{X}$ \\
\hline 25.2 & 80 & 7.9 & 7.78 & $\sqrt{ }$ & & & & & $\mathrm{X}$ \\
\hline 24.8 & 80 & 7.4 & 7.52 & $\sqrt{ }$ & & & & & $\mathrm{X}$ \\
\hline \multicolumn{10}{|c|}{ LMV } \\
\hline $\begin{array}{c}V_{m} \\
(\mathrm{~km} / \mathrm{h})\end{array}$ & $\begin{array}{l}\text { LOAD } \\
(\mathrm{m})\end{array}$ & $\begin{array}{l}S_{m} \\
(\mathrm{~m})\end{array}$ & $\begin{array}{l}S_{k o r} \\
(\mathrm{~m})\end{array}$ & MFDD & & & & & $\begin{array}{c}\text { Acceptable } \\
\text { braking } \\
\text { distance }\end{array}$ \\
\hline 23.9 & 0 & 7.22 & 7.9 & 3.01 & & & & & $\sqrt{ }$ \\
\hline 23.93 & 60 & 8.77 & 9.57 & 2.72 & & & & & $\sqrt{ }$ \\
\hline 24.54 & 140 & 10.9 & 11.31 & 2.26 & & & & & $\sqrt{ }$ \\
\hline 23.51 & 200 & 11.43 & 12.92 & 1.98 & & & & & $\mathrm{X}$ \\
\hline
\end{tabular}

calculates the mean deceleration during the braking. Adding a mechanical brake would greatly improve the results. The battery's SOC did not affect the braking distance.

\section{2. $\mu$-Split Braking Test}

The $\mu$-split brake of the LMV had distortions below $10 \mathrm{~cm}$ which indicates that the LMV remains stable during braking. No data was available of the other multitrack vehicles. The integrated ABS individually interrupts the regenerative braking when a wheel starts slipping as can be seen in Figure 13. The wheel on the lower friction surface has more fluctuations in the wheel velocity. This prevents the wheels from slipping and improves control during braking. The $\mu$-split braking test had on average a $10 \%$ longer braking distance compared to the standard braking test.

\subsection{Steady-State Turn}

The values of the steady-state turn can be seen in Table 5. Babboe City was not tested since this is a single-track vehicle. Babboe Big and City Shopping can reach a velocity of 11 and $13 \mathrm{~km} / \mathrm{h}$ and lateral acceleration of 2.14 and $3.02 \mathrm{~m} / \mathrm{s}^{2}$ 


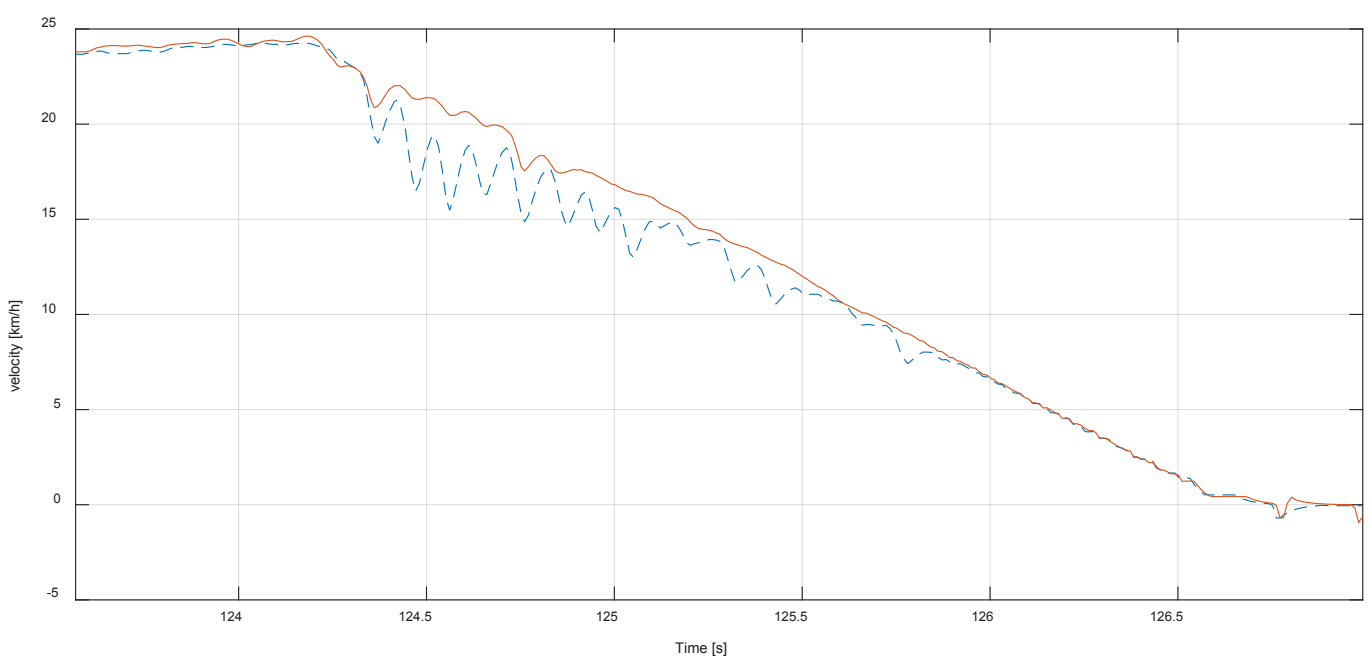

Figure 13. $\mu$-split brake hub motor speed.

Table 5. Steady state-turn.

\begin{tabular}{ccc}
\hline Vehicle & $V_{m}(\mathrm{~km} / \mathrm{h})$ & Lateral acceleration $\left(\mathrm{m} / \mathrm{s}^{2}\right)$ \\
\hline QuadRad & 17.67 & 4.5 \\
City Shopping & 13 & 3.02 \\
Babboe Big & 11 & 2.14 \\
Babboe City & $/$ & $/$ \\
LMV & 17.5 & 0.89 \\
\hline
\end{tabular}

respectively (Figure 14 and Figure 15). The QuadRad and the LMV reached a velocity of 17.67 and $17.50 \mathrm{~km} / \mathrm{h}$. The lateral acceleration achieved was $4.5 \mathrm{~m} / \mathrm{s}^{2}$ and $0.89 \mathrm{~m} / \mathrm{s}^{2}$ (Figure 16 and Figure 17). Although the achieved velocity of the QuadRad and the LMV is similar, the lateral acceleration of the LMV is much lower, due to the ability to lean. The leaning shifts the centre of gravity inwards, which is more comfortable for the driver. The lateral acceleration of the cargo is $6.31 \mathrm{~m} / \mathrm{s}^{2}$ as seen in Figure 16. This large lateral acceleration on the cargo indicates the need for a low cargo area, which results in a low centre of gravity and a stable vehicle. During the maximum speed, the LMV remained stable and was still not tipping over. Driving with and without cargo has no notable difference in maximum velocity. However, the extra weight stabilises the rear module and improves driving comfort.

\subsection{Figure of Eight}

No results were available for the benchmark vehicles. The LMV has a mean maximum velocity of $12.8 \mathrm{~km} / \mathrm{h}$. The respective lateral acceleration is $1 \mathrm{~m} / \mathrm{s}^{2}$. Switching direction causes a lower maximum speed compared to the steady-state turn. The lateral acceleration of the driver during the eight is higher (Figure 18). This may be because the driver leans less due to the changing turns. The maximum acceleration of the cargo is similar to the steady-state turn. 


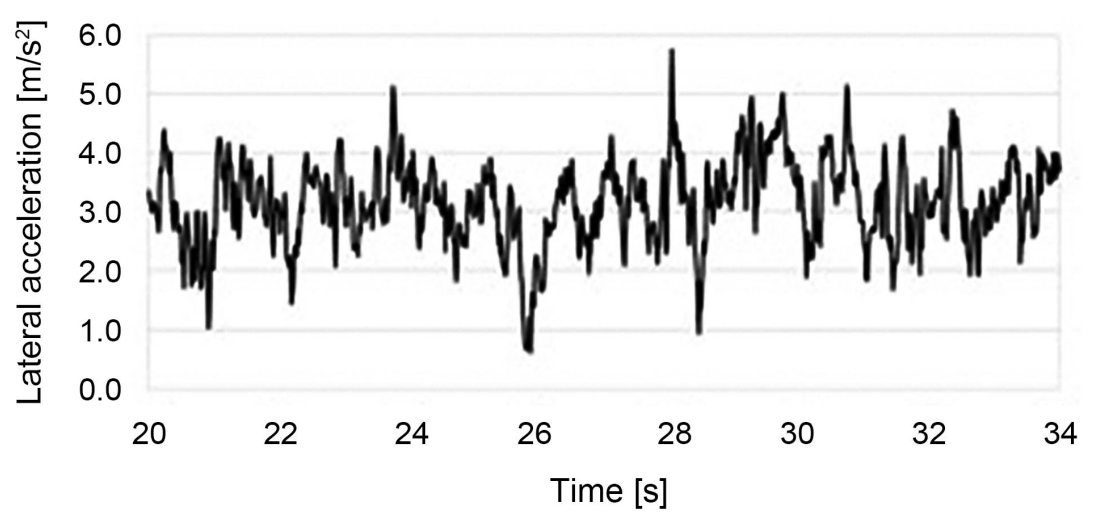

Figure 14. Lateral acceleration of city shopping during steady-state turn.

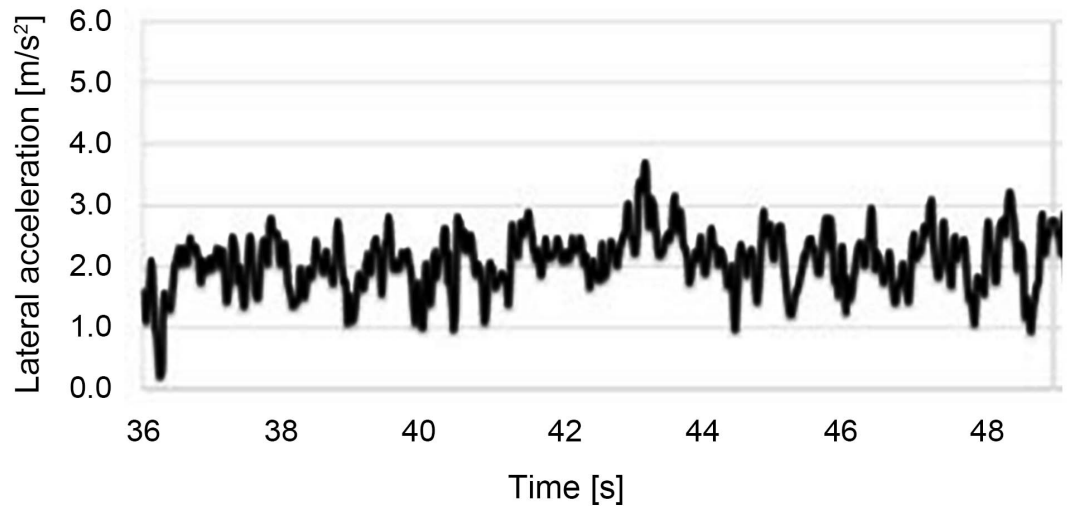

Figure 15. Lateral acceleration of babboe big during steady-state turn.

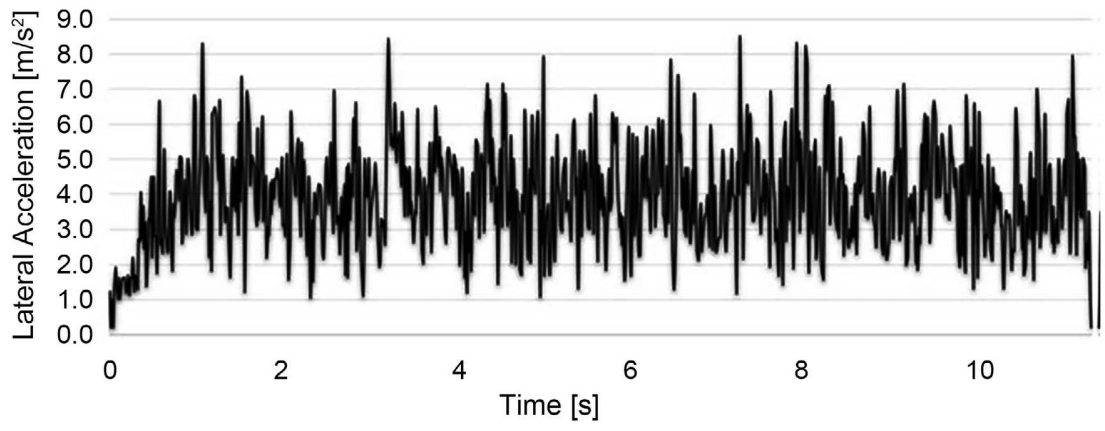

Figure 16. Lateral acceleration of QuadRad during steady-state turn.

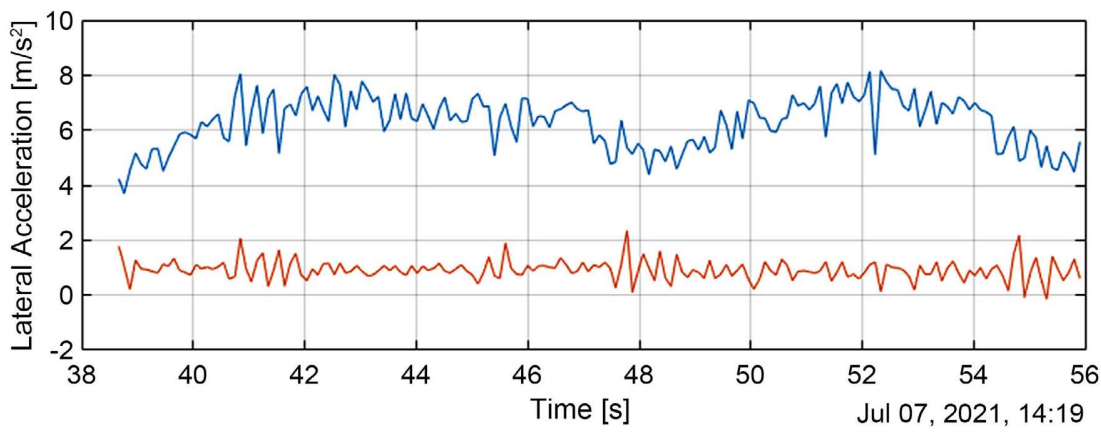

Figure 17. Lateral acceleration of LMV driver and cargo during steady-state turn. 


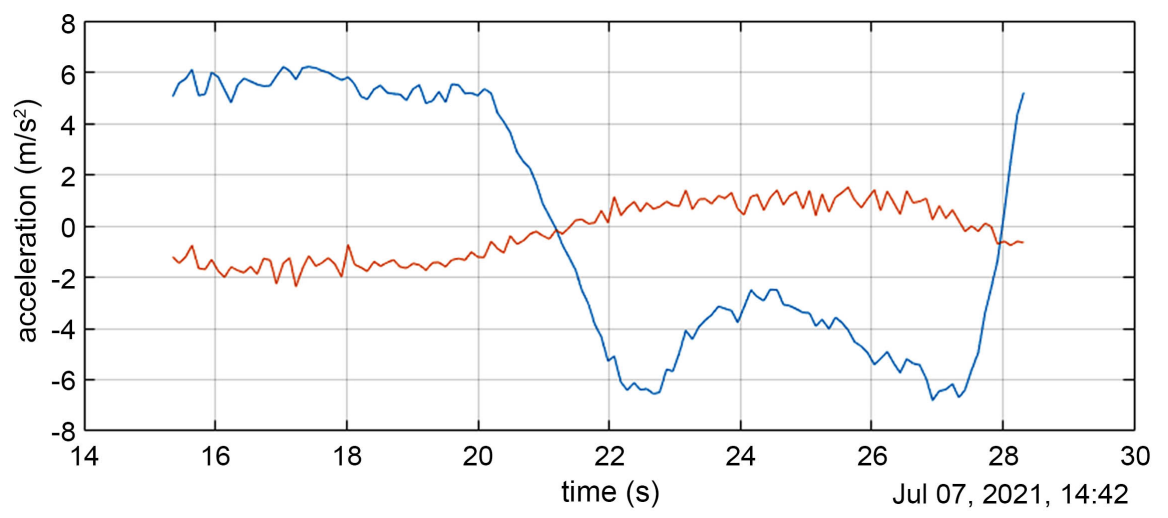

Figure 18. $\mu$-split brake hub motor speed.

\subsection{Prompt Steering}

The values of the Prompt steering can be seen in Table 6. The Babboe City did not participate in the steering input test because it is a single-track vehicle. The extreme steering tests the behaviour of the multitrack vehicles. The flexible frame allowed the LMV to lean during the turn preventing tipping and keeping all wheels on the ground. Due to the long wheelbase, The LMV has a bigger distance even though the turning clearance circle is smaller. The QuadRad and the LMV also performed the test at $15 \mathrm{~km} / \mathrm{h}$ with a distance of $1.9 \mathrm{~m}$ and $2.0 \mathrm{~m}$ respectively. The other vehicles were only carried out at $10 \mathrm{~km} / \mathrm{h}$ for safety reasons. The LMV has similar results with and without cargo but felt more stable with cargo. Driving without cargo has less traction and causes some skidding of the rear wheels while turning.

\subsection{Double Lane Change}

QuadRad can execute the double lane change error-free up to $25 \mathrm{~km} / \mathrm{h}$. The single-track Babboe city can ride through the course at a maximum speed of 20 $\mathrm{km} / \mathrm{h}$. City shopping and Babboe Big can perform the course at $20 \mathrm{~km} / \mathrm{h}$, but the tires already lose contact at $15 \mathrm{~km} / \mathrm{h}$. The LMV can perform the double lane change error-free at a maximum of $20 \mathrm{~km} / \mathrm{h}$. The large width of the LMV makes it considerably more difficult to drive through the course error-free as can be seen in Table 7.

Due to the low clearance on the manoeuvre, the maximum possible speed depends on the driver's driving skills. The best results from 5 drivers differ $5 \mathrm{~km} / \mathrm{h}$. No significant differences were found using different loads. The manoeuvres could be performed at the same velocity with and without cargo. The drivers stated that the LMV was stable and all wheels remained on the ground at all times. The tests with cargo felt even more stable compared to those without. The cargo lowers the centre of gravity and improves the traction of the rear wheels. At higher velocity, the driver is unable to drive through the course without running over cones. The double lane change is also performed on a modified course so clearance is no issue (Figure 10). With these conditions, the driver is able to 
Table 6. Prompt steering.

\begin{tabular}{ccccccccc}
\hline & \multicolumn{3}{c}{ QuadRad } & & \multicolumn{5}{c}{ City Shopping } \\
\hline & $\begin{array}{c}V_{m} \\
(\mathrm{~km} / \mathrm{h})\end{array}$ & $\begin{array}{c}A_{\text {min }} \\
(\mathrm{m})\end{array}$ & $\begin{array}{c}A_{\text {min_ko }} \\
(\mathrm{m})\end{array}$ & Tilting & $\begin{array}{c}V_{m} \\
(\mathrm{~km} / \mathrm{h})\end{array}$ & $\begin{array}{c}A_{\text {min }} \\
(\mathrm{m})\end{array}$ & $\begin{array}{c}A_{\text {min_ko }} \\
(\mathrm{m})\end{array}$ & Tilting \\
\hline $\mathrm{L}$ & 10.2 & 1.3 & 1.25 & No & 10 & 1.6 & 1.6 & No \\
$\mathrm{L}$ & 9.7 & 1.1 & 1.17 & Delay & 11 & 1.6 & 1.32 & No \\
$\mathrm{R}$ & 9.9 & 1.15 & 1.17 & No & 10 & 1.6 & 1.6 & Yes \\
$\mathrm{R}$ & 10.5 & 1.25 & 1.13 & Delay & 11 & 1.9 & 1.57 & Yes \\
\hline & & \multicolumn{1}{c}{ Babboe Big } & & & & LMV & \\
\hline $\mathrm{L}$ & 10 & 2.4 & 2.4 & No & 9.69 & 1.5 & 1.60 & No \\
$\mathrm{L}$ & 10 & 2.5 & 2.5 & No & 9.97 & 1.4 & 1.41 & No \\
$\mathrm{R}$ & 12 & 2.8 & 1.94 & Yes & 9.79 & 1.3 & 1.36 & No \\
$\mathrm{R}$ & 11 & 2.4 & 1.98 & No & 9.81 & 1.35 & 1.40 & No \\
\hline
\end{tabular}

Table 7. Double lane change.

\begin{tabular}{cccccc}
\hline & QuadRad & City Shopping & Babboe Big & Babboe City & LMV \\
\hline $\begin{array}{c}V_{m} \\
(\mathrm{~km} / \mathrm{h})\end{array}$ & Course passed & Course passed & Course passed & Course passed & Course passed \\
\hline 10 & Yes & Yes & Yes & Yes & Yes \\
15 & Yes & Take off & Take off & Yes & Yes \\
20 & Yes & Take off & Take off & Yes & Yes \\
25 & Yes & $/$ & $/$ & $/$ & Yes $^{\mathrm{a}}$
\end{tabular}

a. This was carried out on the adapted double lane change.

go through the course with a maximum velocity of $25 \mathrm{~km} / \mathrm{h}$. During this manoeuvre, the vehicle remains within a track width of 2 meters. These passages carried out at maximum speed were error-free on a course with 0.5 meters of extra clearance. In all tests, the LMV's wheels did not lose contact with the ground. This is thanks to the low centre of gravity and the flexible connection between the driver module and the load module.

\subsection{Slalom}

All vehicles except the LMV could perform both slaloms at prescribed conditions. The LMV was able to perform the $4 \mathrm{~m}$ slalom at $8 \mathrm{~km} / \mathrm{h}$ and the $3 \mathrm{~m}$ slalom was not executed without knocking over pylons. These results are due to the high width of the vehicle. The high vehicle width requires stronger manoeuvres compared to a narrower vehicle and the long wheelbase make the $3 \mathrm{~m}$ slalom too difficult.

\section{Discussion}

The various manoeuvres expose the strengths and weaknesses of the LMV's dy- 
namic behaviour. The steady-state circle and the double lane change show the LMV is a controllable and stable vehicle. The low cargo hold lowers the centre of gravity when the LMV is loaded and improves stability. The flexible connection between the driver and cargo lets the centre of gravity shift inwards during turning. This ensures proper stability during extreme manoeuvres and will prevent tipping over. During every manoeuvre, all wheels kept in contact with the road which was not the case with other multitrack vehicles. The flexible connection also allowed for short turning without losing surface contact as is noted in the turning clearance circle and the prompt steering.

However, the vehicle's width creates extra difficulties during the manoeuvres. The LMV has to take sharper turns compared to the other vehicles when avoiding obstacles. These problems complicate driving in narrow city streets or on bicycle lanes. In combination with the long wheelbase, this made the short slalom not possible. The delta shape concept makes it difficult to estimate whether the vehicle can pass without knocking over cones when there is little room to manoeuvre.

Al tests were performed on a flat asphalt surface since this is the majority of the road the vehicles mainly drive on. However, the vehicle will be deployed in city centres and will drive over cobblestones or through potholes. This test does not consider the influence of bad roads and would be a great addition to the setup where the accelerations are measured driving over different terrains. Multitrack vehicles experience additional lateral shocks compared to single-track vehicles driving over an asymmetrical obstacle. These shocks are extremely uncomfortable for the driver. The flexible connection on the LMV absorbs these shocks for the driver. Furthermore, low-speed tests to control stability are not part of the stability tests. These are not useful for the fixed multitrack vehicles, but the single-track and flexible multitrack vehicles can evaluate the stability of this setup. Busy city streets will force the driver to cycle at walking speed. Preferably this should be possible without putting feet on the ground.

The LMV's vehicle dynamics can be improved upon by changing certain aspects of the vehicle design.

Reducing the wheelbase will ensure an even smaller clearance turning circle. This will facilitate the short turns done in the manoeuvres and may improve the results. Furthermore reducing the width of the vehicle would improve the clearance when driving through narrow courses. The width at the level of the wheels cannot be reduced, but the cargo hold can be narrowed towards the end. This ensures the vehicle swings out less when cornering. Although the braking distance of the cargo bike loaded at full capacity is slightly higher than the other bikes, the braking distance is not sufficient to the regulations at full loading capacity. The regenerative braking still brought the cargo bike to a controlled stop whereas previous research stated brake testing with Babboe city was stopped due to the vehicle being uncontrollable. To improve this, a different hub motor with a higher maximum braking torque or adding a mechanical brake is required. 
The LMV has a decent result compared to the benchmark models. Although the benchmark models represent the different types of cargo bikes, the delta variant (city shopping) does not belong to a commercially usable category. A better comparison can be done by testing additional cargo bikes with similar characteristics. Cargo bikes such as Fulpra, Ono and Cargo Chariot. Those examples have a flexible delta design similar to the LMV. However, these models are hard to come by and are currently very little represented in traffic.

\section{Conclusions}

The manoeuvres prove the cargo bike concept has proper vehicle dynamics independent of the cargo load. Apart from the braking, the results of the manoeuvres were similar with or without a load. The drivers stated the vehicle was even more stable with the load. This is thanks to the low cargo hold. The concept disconnects the drivers module with the cargo module, providing similar cycling feeling to that of a conventional bicycle. The concept vehicle provides extra comfort compared to fixed multitrack vehicles. The hinge allows leaning and significantly lowers the lateral force of the driver compared to fixed frame multitrack vehicles.

The manoeuvres expose the weaknesses of the vehicle's dynamic behaviour. These weaknesses were used to determine various points of improvement.

The concept vehicle does not outperform current cargo bicycles in terms of handling qualities but can be deployed for delivering higher weight and volume parcels. The LMV handles less compared to the QuadRad since the QuadRad has a smaller width and the manoeuvres are beneficial for narrower vehicles.

\section{Conflicts of Interest}

The authors declare no conflicts of interest regarding the publication of this paper.

\section{References}

[1] Verlinghieri, E., Itova, I., Collignon, N. and Aldred, R. (2021) The Promise of LowCarbon Freight. University of Westminster, London. https://static1.squarespace.com/static/5d30896202a18c0001b49180/t/61091edc3acfd a2f4af7d97f/1627987694676/The+Promise+of+Low-Carbon+Freight.pdf

[2] Sheth, M., Butrina, P., Goodchild, A. and McCormack, E. (2019) Measuring Delivery Route Cost Trade-Offs between Electric-Assist Cargo Bicycles and Delivery Trucks in Dense Urban Areas. European Transport Research Review, 11, Article No. 11. https://doi.org/10.1186/s12544-019-0349-5

[3] Wrighton, S. and Reiter, K. (2016) CycleLogistics-Moving Europe Forward! Transportation Research Procedia, 12, 950-958. https://doi.org/10.1016/j.trpro.2016.02.046

[4] Assmann, T. and Behrendt, F. (2017) Determining Optimal Container Heights for Cargobike Crossdocking Schemes in Urban Areas. Proceedings of the 10 th International Doctoral Students Workshop on Logistics, Magdeburg, 20-22 June 2017, 6 p. https://www.researchgate.net/publication/317617634 
[5] Steinmaßl, S. and Lienkamp, M. (2016) Testing and Evaluation of a New Multitrack Electric Bicycle-A Comparative Study. In: Rebelo, F. and Soares, M., Eds., Advances in Ergonomics in Design, Springer, Cham, 743-755. https://doi.org/10.1007/978-3-319-41983-1_67

[6] Alex (2021) Do E-Bikes Need Special Chains. EbikesHQ. https://ebikeshq.com/do-ebikes-need-special-chains/

[7] Williams, T., Kaul, S. and Dhingra, A. (2015) Influence of Frame Stiffness and Rider Position on Bike Dynamics: Analytical Study. Proceedings of the ASME 2015 International Mechanical Engineering Congress and Exposition, Houston, 13-19 November 2015, V04AT04A033. https://doi.org/10.1115/IMECE2015-50137

[8] Pai, S., Neuberger, B. and Buchholz, M. (2021) Adaptive Model Predictive Stabilization of an Electric Cargo Bike Using a Cargo Load Moment of Inertia Estimator. Automatisierungstechnik, 69, 632-642. https://doi.org/10.1515/auto-2021-0032

[9] Pitskhelauri, S.N. (2020) Results of Mathematical and Simulation Modeling of Tricycle Stability against Overturning on a Slope. Naučno-Tehničeskij Vestnik Brânskogo Gosudarstvennogo Universiteta, 6, 418-425.

[10] Rodríguez Licea, M.A., Vazquez Rodríguez, E.A., Perez Pinal, F.J. and Prado Olivares, J. (2018) The Rollover Risk in Delta Tricycles: A New Rollover Index and Its Robust Mitigation by Rear Differential Braking. Mathematical Problems in Engineering, 2018, Article ID: 4972419. https://doi.org/10.1155/2018/4972419

[11] Mamiti, G.I., Pliev, S.K. and Tedeev, V.B. (2015) Stability of a Tricycle with Inclination of the Body. Russian Engineering Research, 35, 733-736.

https://doi.org/10.3103/S1068798X15100135

[12] Meijaard, J.P., Papadopoulos, J.M., Ruina, A. and Schwab, A.L. (2013) Linearized Dynamics Equations for the Balance and Steer of a Bicycle: A Benchmark and Review. Russian Journal of Nonlinear Dynamics, 9, 343-376.

https://doi.org/10.20537/nd1302010

[13] The European Parliament and the Council of the European Union (2013) On the Approval and Market Surveillance of Two- or Three-Wheel Vehicles and Quadricycles. Regulation (EU) No 168/2013.

[14] ISO (2015) Cycles-Safety Requirements for Bicycles. Part 2: Requirements for City and Trekking, Young Adult Mountain and Racing Bicycles. European Committee for Standardization, ISO 4210-2:2015.

[15] ISO (2021) Passenger Cars-Validation of Vehicle Dynamics Simulation-Lateral Transient Response Test Methods. International Organization for Standardization, ISO 22140:2021.

[16] Wilson, D.G. and Schmidt, T. (2020) Bicycling Science. 4th Edition, MIT Press, Cambridge, MA. https://doi.org/10.7551/mitpress/11660.001.0001

[17] Kooijman, J.D.G. and Schwab, A.L. (2011) A Review on Handling Aspects in Bicycle and Motorcycle Control. Proceedings of the ASME 2011 International Design Engineering Technical Conferences and Computers and Information in Engineering Conference, Washington DC, 28-31 August 2011, 597-607.

https://doi.org/10.1115/DETC2011-47963

[18] UNECE (2015) Uniform Provisions Concerning the Approval of Vehicles of Categories L1, L2, L3, L4 and L5 with Regard to Braking. Regulation No. 78 of the Economic Commission for Europe of the United Nations (UNECE). Regulation No 78.

[19] Li, L., Li, X.J., Wang, X.Y., Song, J., He, K. and Li, C.F. (2016) Analysis of Downshift's Improvement to Energy Efficiency of an Electric Vehicle during Regenerative Braking. Applied Energy, 176, 125-137. https://doi.org/10.1016/j.apenergy.2016.05.042 
[20] Reference Tables for Physical Setting/Chemistry. 2011 Edition, The University of the State of New York, Albany, NY. http://www.kentchemistry.com/newRT.pdf

[21] Xue, Z.J., Li, C.F., Wang, X.Y., Li, L. and Zhong, Z.H. (2020) Coordinated Control of Steer-by-Wire and Brake-by-Wire for Autonomous Emergency Braking on Split- $\mu$ Roads. IET Intelligent Transport Systems, 14, 2122-2132.

https://doi.org/10.1049/iet-its.2020.0184

[22] Bulsink, V.E., Doria, A., Van de Belt, D. and Koopman, B. (2015) The Effect of Tyre and Rider Properties on the Stability of a Bicycle. Advances in Mechanical Engineering, 7, Article ID: 168781401562259. https://doi.org/10.1177/1687814015622596 